\title{
O debate desenvolvimentista no Brasil: tomando partido *
}

\author{
Maria de Lourdes Rollemberg Mollo ** \\ Adriana Moreira Amado **
}

\begin{abstract}
Resumo
$\mathrm{O}$ artigo analisa as várias vertentes do desenvolvimentismo, procurando destacar as suas origens teóricas e justificar, por meio delas, as diferentes prescrições de políticas econômicas. Em seguida, o artigo toma partido no debate, por meio de discussão resenhada dos trabalhos recentes sobre os modelos de crescimento export-led, demand-led, debt-led, profit-led e wage-led.
\end{abstract}

Palavras-chave: Desenvolvimentismo; Novo desenvolvimentismo; Social desenvolvimentismo; Heterodoxias econômicas; Estado.

\section{Abstract \\ The developmentalism debate in Brazil: taking sides}

The article analyzes the different approaches to "developmentalism", emphasizing its theoretical origins, and highlighting them as the source of different economic policy propositions. The paper then takes the side of one of the approaches, based on theoretical and empirical articles on different growth regimes in Brazil, such as export-led, demand-led, debt-led, profit-led and wage-led.

Keywords: Developmentalism; New developmentalism; Social developmentalism; Economic heterodoxies; State.

JEL B50, O11, O23.

\section{Introdução}

O objetivo deste artigo é contribuir para o debate recente no interior da agenda desenvolvimentista. Como se sabe, após décadas de neoliberalismo no Brasil e no mundo, voltamos a rediscutir o desenvolvimento como estratégia deliberada e não levada a cabo apenas pelas forças do mercado. Devemos isso, em particular, a Bresser-Pereira (1991, 2004, 2006, 2007, 2011), cujos trabalhos foram precursores ao proporem o chamado novo desenvolvimentismo.

Diferentemente dos trabalhos do mainstream que veem o crescimento causado por fatores ligados à oferta, mais particularmente à quantidade, alocação e produtividade dos fatores de produção, devendo ser deixado ao mercado, o

\footnotetext{
* Trabalho recebido em 14 de fevereiro de 2014 e aprovado em 8 de setembro de 2014.

** As autoras são professoras do Departamento de Economia da Universidade de Brasília, DF, Brasil. ( $\underline{\mathrm{UnB}}$ ) / Pesquisadoras do Conselho Nacional de Desenvolvimento Científico e Tecnológico (CNPq) a quem agradecem por financiamento para pesquisa maior, da qual este artigo é um dos frutos. E-mails: mlmollo@unb.br e uctpama@unb.br, respectivamente.
} 
desenvolvimentismo se coloca como heterodoxia, não apenas por contemplar um papel deliberado do Estado para garantir crescimento e transformação da sociedade, mas também porque apreende os fatores do lado da demanda como os motores do crescimento. Isso não significa que fatores do lado da oferta, como os que inibem o investimento, não sejam também objeto de políticas de desenvolvimento e requeiram, para a heterodoxia, a intervenção do Estado. É o caso, por exemplo, das deficiências de inovações e infraestrutura. O que ocorre é que esses fatores do lado da oferta podem impedir o desenvolvimento, mas sua solução pode não estimular, por si só, o aumento da produção. Este é estimulado, segundo a heterodoxia, quando há aumento da demanda. Assim, as análises de caráter heterodoxo apontam no sentido da necessidade da ação deliberada do Estado para efetuar as transformações estruturais necessárias ao crescimento e ao aproveitamento pleno dos estímulos de demanda ${ }^{1}$.

Aí acabam, porém, os acordos, e os debates que ora se verificam no interior do desenvolvimentismo brasileiro, acham-se centrados no tipo de demanda que se quer estimular para garantir o crescimento, com consequências sobre as prescrições de políticas privilegiadas em cada abordagem.

$\mathrm{O}$ artigo se organiza de maneira a analisar as várias vertentes do desenvolvimentismo no primeiro item e, no segundo, toma partido no debate por meio de discussão resenhada dos trabalhos recentes sobre os modelos de crescimento export-led, demand-led, debt-led, profit-led e wage-led. Ao final do artigo, algumas considerações mostram a melhor adequação da proposta social-desenvolvimentista para a perspectiva de desenvolvimento brasileiro.

\section{As várias perspectivas de desenvolvimentismo no Brasil}

O primeiro ramo do desenvolvimentismo, que aqui denominaremos de desenvolvimentismo precursor, tem como um de seus líderes mais marcantes Bresser-Pereira (1991, 2004, 2005, 2007, 2011). Esta perspectiva, bem como a maioria delas, tem alguns vínculos com as ideias cepalinas. Todavia, dentro da própria CEPAL havia algumas diferenças de ênfases em certos aspectos teóricos que também aparecem como determinantes no debate atual.

As ideias da Cepal estão profundamente associadas à discussão do desenvolvimento econômico e, portanto, às tendências de longo prazo da economia (Furtado, 1961), ainda que em alguns momentos se observem as interfaces destas com as determinantes de modelos focados no curto prazo. Essas ideias surgem de uma perspectiva heterodoxa que baseava sua análise em elementos bastante diversos de várias vertentes do pensamento, sem grandes compromissos por opções teórico-

(1) Além disso, quanto mais a perspectiva tiver cunho keynesiano, mais a demanda impulsiona a oferta, ao contrário da perspectiva neoliberal ortodoxa, em que a oferta cria sua própria procura. 
metodológicas bem definidas. Na construção do pensamento da Cepal havia uma grande liberdade criadora no sentido de buscar elementos que conseguissem compor a história do desenvolvimento econômico latino-americano. Contudo, parte da abordagem ainda era ortodoxa. Na falta de elementos concretos consolidados que permitissem a análise diferenciada, era à tradição ortodoxa que se acabava recorrendo.

A ênfase da análise do desenvolvimento dos trabalhos da Cepal estava focada nas questões ligadas aos fatores reais que interferem sobre a economia. A dinâmica monetária, em termos teóricos, era relegada a um segundo plano e, quando emergia, estava profundamente baseada em uma perspectiva de natureza ortodoxa. Algumas explicações para isso podem ser apresentadas. A mais contundente referese ao fato de que, do ponto de vista teórico, as contribuições mais marcantes de Keynes, no momento em que estavam sendo gestadas as ideias da Cepal, eram as questões econômicas reais. Estas foram largamente utilizadas pela Cepal em seus trabalhos. Apesar da ênfase clara e óbvia dos escritos de Keynes na moeda e em seus efeitos de curto e longo prazo para o emprego e para o investimento, estes elementos só passaram a ser vistos como centrais depois da década de 1970, com o surgimento consistente da escola Pós-Keynesiana, que focava suas análises no conceito de "Economia Monetária de Produção" estabelecido como base para a análise de uma economia monetária moderna.

De fato, a relevância da análise conjunta dos elementos reais e monetários para entender a dinâmica de acumulação de uma economia capitalista ficou óbvia com a publicação dos Collected Writings, em especial do volume XXIX, que só foi publicado em 1979. Conforme destaca Carvalho (1992, p. 171), a Teoria Geral e os artigos de 1937 e 1938, assim como o material do mencionado volume XXIX são fundamentais para a construção do pensamento da escola Pós-Keynesiana. O esforço de Keynes de mostrar uma teoria diferente da neoclássica ficou, portanto, "em grande parte inédito por muito tempo" o que justifica a sua não utilização pelo pensamento cepalino.

Apesar, porém, da ênfase ser sobretudo na análise dos fatores econômicos reais, a análise da Cepal é heterodoxa por buscar intervir para transformar a realidade concreta, conforme colocado por Rosa Furtado na nova edição do livro "Desenvolvimento e Subdesenvolvimento" de Celso Furtado. Ela diz, referindo-se à atitude de Furtado: "Como sempre fez: teorizar, sim, mas para agir" (Furtado, 2009).

Nesse sentido, há alguns elementos que marcam o pensamento da Cepal, dando-lhe o caráter de escola do pensamento econômico, e eles estão todos baseados no método histórico-estrutural. Esta perspectiva era o que permitia entender o desenvolvimento como um fenômeno histórico e institucionalmente marcado, o que impedia que modelos baseados em elementos abstratos e partindo de um método 
hipotético dedutivo tivessem relevância para a explicação dos fenômenos do desenvolvimento concreto. Ao contrário, a percepção era a da necessidade de uma perspectiva indutiva para tratar desses fenômenos. Como observava Furtado (2009, p. 25), o estudo do desenvolvimento deve se dar em dois planos:

O primeiro - no qual predominam as formulações abstratas - (...). O segundo que é o plano histórico - abrange o estudo crítico, em confronto com uma realidade dada, das categorias básicas definidas pela análise abstrata. Não basta construir um modelo abstrato e elaborar a explicação do seu funcionamento. Igualmente importante é a verificação do seu funcionamento (...). Somente essa verificação poderá indicar as limitações decorrentes do nível de abstração em que foi elaborado o modelo e sugerir as modificações a serem introduzidas para fazê-lo válido do ponto de vista de uma realidade dada.

e mais:

O esforço no sentido de alcançar níveis mais altos de abstração deve ser acompanhado de outro objetivando definir, em função de realidades históricas, os limites de validez das relações inferidas. A duplicidade fundamental da ciência econômica- seu caráter abstrato e histórico- aparece, assim, com toda a plenitude na teoria do desenvolvimento econômico (Furtado, 2009, p. 26).

Nesse sentido, o subdesenvolvimento é visto como "um processo histórico autônomo, e não uma etapa pela qual tenham, necessariamente, passado as economias que já alcançaram grau superior de desenvolvimento" (Furtado, 2009, p. 161)

Partindo, pois, desses elementos próprios ao subdesenvolvimento, desenvolve-se a perspectiva cepalina em que os aspectos histórico-estruturais são os que explicam a sua realidade. Dentre esses elementos cabe destacar a ênfase posta na questão do subdesenvolvimento como elemento associado ao próprio desenvolvimento capitalista, caracterizado por uma heterogeneidade estrutural marcante e pela inserção periférica de sistemas com essas características no comércio internacional. Nesse caso específico, observa-se que essa inserção está vinculada a uma série de elementos estruturais das economias periféricas que geram uma tendência de longo prazo de transferência dos ganhos do progresso técnico da periferia para o centro e que minam a possibilidade de dinamização que este poderia ter sobre aqueles subsistemas. As explicações para essa questão estão associadas às estruturas de mercado prevalecentes na periferia (mercado de trabalho e de bens) e às elasticidades-renda e preços dos produtos que caracterizam as pautas de exportação e importação daqueles países (Rodriguez, 1981).

Esses elementos tenderiam a gerar uma tendência a uma distribuição de renda extremamente perversa, que colocava pressão extra sobre o equilíbrio do 
balanço de pagamentos e inviabilizava a dinamização do mercado interno em função de uma estrutura de demanda incompatível com a oferta.

Contudo, o foco permanente da discussão sobre o desenvolvimento está na dependência tecnológica da periferia. Esta geraria o agravamento de problemas associados à produtividade e à utilização dos recursos dos países periféricos e tenderia a agravar as restrições associadas ao Balanço de Pagamentos dessas economias. Como coloca Furtado (2009, p. 173): "é a heterogeneidade tecnológica entre setores ou departamentos de uma mesma economia que caracteriza o subdesenvolvimento." E ainda:

é específica do subdesenvolvimento essa falta de correspondência entre a disponibilidade de recursos e fatores e as combinações destes requeridas pela tecnologia que está sendo absorvida. $\mathrm{O}$ que se explica pelo fato de que o subdesenvolvimento não resulta de transformações endógenas de uma economia pré-capitalista, mas de um processo de enxerto, nesta última, de uma ou mais empresas ligadas ao comércio das economias industrializadas em expansão (Furtado, 2009, p. 174).

Esses elementos interagem e se retroalimentam: agrava-se o problema do excesso estrutural de mão de obra, das restrições do Balanço de Pagamentos e das pressões de custos induzidas por esses elementos. Ao mesmo tempo, aprofunda-se a heterogeneidade estrutural do mercado de trabalho com diferenciais marcados e ampliados de produtividade e salários no setor arcaico e dinâmico.

A saída para o subdesenvolvimento latino-americano encontra-se então na superação desses entraves estruturais e está associada ao desenvolvimento tecnológico, à diversificação econômica baseada no mercado interno e em sua dinâmica. Contudo, essa possibilidade não é viável com base nos mecanismos de mercado. Entra, nesse momento, a necessidade premente da ação coordenadora e planejadora do Estado como elemento exógeno fundamental para a superação dessa dinâmica econômica propagadora do subdesenvolvimento (Bielschowsky, 2010).

A análise estruturalista dá sustentação a várias das perspectivas do chamado desenvolvimentismo. Todavia, o artigo procurará demonstrar que algumas partes são resgatadas por uma vertente do desenvolvimentismo e outras são salientadas por outras, levando à distinção entre os três tipos de desenvolvimentismos aqui analisados. Tentaremos, assim, classificar as várias vertentes aludidas e identificar sua filiação teórica.

$\mathrm{Na}$ classificação que faremos aqui, distinguiremos os novos desenvolvimentistas precursores, de pensamento mais próximo dos neoclássicos, em especial em virtude do papel atribuído à poupança, embora se apresente como keynesiano; o segundo grupo é o de novos desenvolvimentistas pós-keynesianos, que tem em particular membros da UFRJ - Universidade Federal do Rio de Janeiro. O 
terceiro grupo tem natureza estruturalista também, mas trabalha com uma perspectiva mais próxima dos estruturalistas de esquerda, contendo ideias póskeynesianas, em particular sobre o papel mais discricionário do Estado, sendo mais próximo do marxismo em vista da preocupação mais associada à melhor inserção do trabalhador na relação capital-trabalho. Esse terceiro grupo é o dos socialdesenvolvimentistas.

De forma a melhor apreendermos as razões teóricas que sustentam as prescrições de políticas dos três grupos, chamaremos atenção para alguns tópicos de desacordo quanto ao papel do Estado e da moeda, que os levam a perceber políticas de natureza distintas.

\section{Estado e desenvolvimento: ortodoxia $\mathrm{X}$ heterodoxia em matéria monetária}

Para entender o processo de crescimento da atividade econômica, para a economia liberal ortodoxa, incluindo-se nela tanto o pensamento neoclássico, quanto o novo-clássico e o novo-keynesiano, o mercado de fundos de empréstimos é fundamental. É ele que explicita os determinantes da poupança e do investimento, e estabelece o caráter fundamental da poupança para financiar o investimento e, então, o crescimento do produto e da renda de forma sustentável e não inflacionária. De fato, neste mercado a oferta de fundos de empréstimos se confunde com a poupança, que é toda a renda recebida e não gasta. A demanda, por sua vez é o investimento. Do lado da oferta, sabemos, a taxa de juros é a recompensa pela desutilidade marginal da espera para consumir só no futuro, e do lado da demanda ela é a recompensa pela contribuição marginal do investimento para a produção. Ao respeitar as vontades privadas individuais de poupar, o mercado tende a ser o melhor regulador porque reduz o gasto de consumo e, com isso, abre espaço para a realização de outros gastos, os de investimento, sem que isso pressione os preços.

Por outro lado, a espera para consumir apenas no futuro garante que só após o investimento realizado, quando os bens estiverem disponíveis, a demanda por consumo se fará sentir e será satisfeita de forma equilibrada, o que, de novo, garante estabilidade de preços. Nesse sentido, a poupança é importante não apenas para financiar o investimento, mas para garantir os bens necessários ao consumo a cada data, tudo isso garantindo preços estáveis. Nessas condições, qualquer tentativa do Governo de estimular o crescimento via aumento de consumo ou investimento, ou via criação de moeda que estimule a demanda privada tende a pressionar os preços por aumento liquido de gastos, já que, para esses autores, tais impulsões monetárias não ampliam o investimento de forma duradoura, uma vez que a moeda é considerada neutra a curto ou a longo prazo. Daí a necessidade de poupança prévia sempre que se pensa no investimento e no crescimento. 
A esse tipo de argumentação, que estabelece o caráter regulador do mercado de fundos de empréstimos sobre o crescimento econômico sustentável e estável, adiciona-se o caráter desestabilizador da intervenção governamental por meio da política fiscal, com o argumento de crowding-out para negar seus efeitos sobre o estímulo ao crescimento econômico. Para gastar com a política fiscal, e assim estimular o crescimento, o governo se endivida ou tributa. No primeiro caso, eleva a taxa de juros e no segundo abala a confiança dos empresários e, nos dois casos, segundo a ortodoxia econômica, reduz o investimento privado, redução que neutraliza o investimento governamental.

Do ponto de vista da política monetária, as prescrições ortodoxas relacionam-se com a aceitação a curto ou a longo prazo de alguma versão da teoria quantitativa da moeda, e, em particular, com o argumento de neutralidade da moeda já mencionado. É por considerar que a moeda não afeta de forma duradoura os fatores reais da economia, como produção ou emprego, que a ortodoxia liberal nega um papel à política monetária no estímulo ao crescimento. De fato, só o argumento de neutralidade da moeda a curto ou a longo prazo garante que uma impulsão monetária tenha como única consequência a inflação, uma vez que não afeta de forma duradoura a produção e o emprego.

A heterodoxia econômica nega esse raciocínio, o que torna o papel do Estado importante tanto do ponto de vista fiscal como monetário, mas nega em graus diferentes, razão pela qual a separamos em três grupos a serem analisados a seguir.

\subsection{Os novos desenvolvimentistas precursores}

Os novos desenvolvimentistas precursores insistem em priorizar o mercado externo pelo crescimento das exportações como mola propulsora do desenvolvimento buscado, e justifica a denominação "novo desenvolvimentista", que os torna diferentes do desenvolvimentismo dos anos 1950 e 1960 (BresserPereira, 2006, 2007, 2010), por escolher tal prioridade distinta, mas também e, sobretudo, por contemplar melhor a necessidade de equilíbrio fiscal. Essa lógica é inspirada em uma percepção dos anos 90 sobre o desenvolvimento export-led na Ásia, onde supostamente houve equilíbrio fiscal, em contraste com o modelo de substituição de importações da América Latina. Atribuem ao desenvolvimentismo antigo certa irresponsabilidade fiscal que desejam evitar. A semelhança, contudo, dos argumentos deste grupo com o raciocínio de Prebisch chama atenção.

Para os estruturalistas cepalinos, em particular Prebisch (1961, p. 7), o desenvolvimento dos países periféricos "está intimamente ligado ao curso das exportações", cujo ritmo "impõe limites ao desenvolvimento espontâneo da economia", uma vez que limita as importações necessárias ao crescimento. Por outro lado, a retração "costuma despertar (...) aquelas forças inflacionárias que estão 
sempre latentes na economia latino-americana". São questões estruturais que requerem uma política anticíclica do Estado. Esta, porém, é dificultada por insuficiência de poupança e outros fatores que conduzem à inflação. Para ele, "a inflação ocorre porque a economia é estruturalmente vulnerável, porque existem fatores regressivos de distribuição de renda, porque há insuficiência de poupança para acelerar as inversões, dada uma estrutura econômica e social" (Prebisch, 1961, p. 10$)^{2}$. Observa-se aqui que as exportações impõem limites ao desenvolvimento dentro do marco de uma economia periférica e em função das restrições estruturais do Balanço de Pagamentos, conforme já mencionado ao citar Furtado (2009). Ou seja, são as questões estruturais do subdesenvolvimento que estão impondo esses limites e a inserção periférica no comércio internacional que estão gerando esses resultados.

Assim, cabe ao Estado "fazer desaparecer a demanda excessiva de importações e desviá-la internamente para manter, em forma não inflacionária, a demanda de fatores produtivos empregados nas atividades de inversão" (Furtado, 1961, p. 47); "manter o volume de inversões antes realizadas inflacionariamente, cobrindo-as, porém, com poupança proveniente de impostos e da contribuição de recursos internacionais" (Furtado, 1961, p. 21); introduzir reformas estruturais no próprio Estado, que "terá que estabelecer uma clara distinção entre gastos crescentes da administração e as inversões internas que devem crescer ao ritmo imposto, de um lado por considerações de política econômica e social, e de outro pelas importações de bens de capital" (Furtado, 1961, p. 31) .

Observe-se, nessas frases, que a questão da necessidade de poupança para garantir o investimento é uma questão básica, e que dessa insuficiência se salta para a consequência inflacionária, justamente porque, como mencionado ao expor o pensamento ortodoxo, na inexistência de redução dos gastos de consumo que garanta espaço para os gastos de investimento, a inflação é o resultado. Esse resultado só ocorre porque a moeda é considerada neutra, não podendo o crédito, sem lastro em poupança prévia, estimular o aumento duradouro da produção e da capacidade produtiva. Essa é uma posição, portanto, do ponto de vista teórico, muito próxima dos economistas ortodoxos, porque o argumento do mercado de fundos de empréstimos é preservado integralmente. Cabe ressaltar que essa aproximação dos neoclássicos em matéria monetária não os faz acreditar, todavia, que os problemas do subdesenvolvimento serão resolvidos com uma perspectiva neoclássica mais geral.

(2) Estamos nos referindo aqui apenas aos argumentos que nos servirão para classificar os vários tipos de desenvolvimentismo, embora vários sejam os fatores estruturais, segundo a Cepal, que explicam os problemas da América Latina para o desenvolvimento.

(3) Ou seja, a dinâmica de produção priorizada é a interna, enquanto o mercado externo se coloca como restrição. 
A abordagem precursora embora encabeçada por Bresser-Pereira, (1991, 2002, 2004, 2006, 2007 e 2011), é defendida por outros como Nakano (BresserPereira; Nakano, 2002), Gala (Bresser-Pereira; Gala, 2007) e, mais recentemente, por Oreiro (2012). Nessa concepção destaca-se como especificidade a ideia de orientar a economia para as exportações, condicionando o aumento dos investimentos à diminuição da taxa de juros e, mais particularmente, à existência de uma taxa de câmbio competitiva. A "variável-chave" da política de desenvolvimento, nesse sentido, deve ser a taxa de câmbio (Bresser-Pereira, 2010, p. 669), porque, ao contrário do antigo desenvolvimentismo, que dava prioridade ao mercado interno, a industrialização deve ser "orientada para as exportações"; tratase, em suas palavras, de propor um "modelo exportador", capaz de aproveitar vantagens locais, como a mão de obra barata (Bresser-Pereira, 2010, p. 679). Esse tipo de abordagem parece fundamentado nos vários modelos de crescimento com restrição de Balanço de Pagamentos, dos quais os estruturalistas são um subgrupo, mas que também encontram respaldo na vasta literatura originada dos modelos de Thirwall (1980, 1982).

Cabe ressaltar que a perspectiva estruturalista é bem mais ampla do que apenas de estímulo ao setor exportador. O estímulo ao setor exportador pode não ter impacto nenhum em termos das trajetórias de crescimento da economia se reformas estruturais profundas não forem realizadas. O problema do subdesenvolvimento não está associado apenas aos limites das exportações, conforme mencionado anteriormente e destacado por Rodriguez (1981), mas os limites impostos pelas exportações são consequência dos problemas estruturais característicos do subdesenvolvimento, em que a heterogeneidade estrutural e a dependência tecnológica desempenham papel chave. Nessa proposta, nenhum desses dois problemas é abordado. O simples foco no setor exportador, muito pelo contrário, pode aprofundar os dois problemas, uma vez que não existe nenhuma garantia de que o tipo de medida adotada será suficiente para reverter ou realinhar a estrutura do comércio exterior da periferia a uma estrutura funcional ao crescimento, ou seja, com uma estrutura com elasticidades de exportação e importação que permitam a superação dos entraves impostos pelo comércio exterior ao crescimento. Essa superação, sim, é uma questão de fundo que passa por elementos mais complexos do que as propostas que ora se colocam. Para promover essas mudanças de natureza estrutural é fundamental a participação do Estado e do planejamento econômico.

A ideia de que o problema de insuficiência de poupança era o hiato mais restritivo ao desenvolvimento, como lembra Bielschowsky, é comum também nos textos de Furtado ${ }^{4}$, o que o tornava um "keynesiano atípico" (Bielschowsky, 1988,

(4) Observe-se, por exemplo, as referências de Furtado ao déficit de poupança como razão do subdesenvolvimento em Desenvolvimento e Subdesenvolvimento (Furtado, 1961, p. 183 e 206) e em publicações mais novas como O Capitalismo Global (Furtado, 1998, p. 60). 
p. 160), já que para os economistas keynesianos, as economias avançadas sofriam de excesso de poupança. Embora Aníbal Pinto chamasse atenção para os problemas relativos ao financiamento via crédito, essa era uma questão pouco explorada em geral pela Cepal.

Seja em função da importância dada à poupança prévia, ou em vista das preocupações inflacionárias, seja mais recentemente, na prescrição de redução salarial -independente daquela que surge da desvalorização cambial - para garantir competitividade às exportações (Oreiro, 2012a; 2012b) os novos desenvolvimentistas precursores colocam-se entre os mais conservadores. Quanto à poupança prévia, em obras mais recentes, Bresser-Pereira (2011) se coloca explicitamente contra isso, aproximando-se dos novos desenvolvimentistas póskeynesianos que veremos a seguir. Continua, porém, preocupado com o impacto inflacionário das políticas econômicas, como se elas fossem incapazes, seja do ponto de vista fiscal ou monetário, de alavancar a produção de forma duradoura, para permitir o próprio arrefecimento da inflação a médio prazo, o que significa conceber a moeda como neutra.

Por outro lado, ao invés de buscar, como insistia o próprio Prebisch (1961, p. 35), "um esforço deliberado de atuar sobre as forças da economia a fim de acelerar seu crescimento, não pelo crescimento mesmo, mas como meio de conseguir um melhoramento persistente da renda nos grupos sociais de rendas inferiores e médias e sua participação progressiva na distribuição da renda global”, sugerem, ao contrário,que se "promova moderação salarial" (Oreiro, 2012a, p. 29), afirmando que "um regime de crescimento wage-led é insustentável a longo prazo", porque "um aumento cumulativo da participação dos salários na renda irá resultar, em algum momento, em uma tendência a queda da taxa de lucro" (Oreiro, 2012a, p. 32), o que interromperá o crescimento do nível de renda e de produção e levará à instabilidade política. Discutiremos essas afirmações no item 2, ao tomarmos partido do desenvolvimentismo social.

Uma vez que esta proposta não apresenta elementos claros para a transformação estrutural da economia brasileira que viabilizem o desenvolvimento tecnológico autônomo e que reduzam a heterogeneidade estrutural da economia, ela perde traços estruturalistas. Esse tipo de proposta pode levar, assim, a um agravamento da distribuição de renda e à ampliação da heterogeneidade interna da economia, ampliando os drenos do progresso técnico através do mecanismo salarial e cambial, contrastando, nesse sentido, com a perspectiva estruturalista.

A preocupação dos novos desenvolvimentistas precursores com os salários e a prescrição de reduzi-los também os diferencia do próximo grupo. Isso porque se, conforme Carneiro (2012), as propostas pós-keynesianas não fazem maiores considerações sobre o papel do Estado na melhoria da distribuição da renda, aqui há 
sim uma proposta de interferência na distribuição da renda, tornando-a mais regressiva.

\subsection{Os novos desenvolvimentistas pós-keynesianos}

Embora o novo desenvolvimentismo tenha surgido como uma perspectiva única, a proposta de classificação deste grupo como diferente do primeiro deve-se, por um lado, à filiação pós-keynesiana mais clara e, por outro, às prescrições distintas de política econômica. Quanto a essas, embora foquem também no mercado externo, sua preocupação maior é evitar a vulnerabilidade à qual fica sujeito o país quando a economia encontra-se aberta, em particular às entradas e saídas de capitais, o que é um traço mais heterodoxo desta abordagem. Apoiados nos últimos escritos de Keynes, os pós-keynesianos, centram sua crítica à ortodoxia na falta de percepção da incerteza que permeia a economia e analisam a partir daí a necessidade de um papel ativo do Estado. A preocupação com o viés inflacionário dos governos, por sua vez, não se coloca, em vista da percepção de moeda não neutra.

A crítica pós-keynesiana ao instrumental ortodoxo, tal como queria Keynes (1971-1983), chama atenção para o irrealismo de um mercado em que a incerteza que provém do futuro desconhecido e do desconhecimento do resultado das decisões econômicas descentralizadas está ausente. De fato, em uma situação de incerteza não é possível avaliar e então comparar a (des)utilidade marginal de esperar para consumir no futuro e a taxa de juros para determinar a poupança do ponto de vista ortodoxo. É essa mesma incerteza que se acha ausente quando toda a poupança é vista como oferecida como fundos de empréstimos, não havendo espaço para o entesouramento ou preferência pela liquidez. Por outro lado, a incerteza do ponto de vista do investimento impede que se possa, de fato, calcular a rentabilidade marginal do mesmo. Para Keynes, pode-se apenas conjecturar a respeito, razão pela qual chamou tal rentabilidade de eficiência marginal do capital, contrapondo-a à produtividade marginal dos ortodoxos. Todas essas divergências o levam a rejeitar in totum o mercado de fundos de empréstimos neoclássico (Keynes, 1983a e 1983b).

De fato, para Keynes (1983a e 1983b) não é preciso haver poupança prévia para que o investimento se verifique. Basta que haja crédito em condições de juros razoáveis quando comparadas com o da eficiência marginal do capital, e a decisão de investir se viabilizará (finance motive). Também não há porque se preocupar com o volume de poupança. Ela será igual ao montante deste investimento, uma vez que ele tenha sido realizado (ex-post), porque ele levará ao crescimento multiplicado da renda da qual depende a poupança para Keynes. Assim, o investimento não precisa de poupança, mas sim de crédito a taxas de juros baixas. Finalmente, após o investidor tomar os primeiros empréstimos, geralmente de curto prazo (finance motive), para viabilizar as primeiras ações de investimento, é preciso que o investidor busque outros de prazo mais longo, compatíveis com os de maturação do seu 
investimento. Esses recursos (funding) estarão disponíveis nos mercados financeiros quanto mais densos eles forem em termos de quantidades de produtos - com rentabilidades e prazos distintos - porém sua disponibilidade não dependerá do montante da poupança, mas sim da preferência dos poupadores pela liquidez. Assim, de novo, não há, para Keynes, razão para se preocupar com a poupança no processo de investimento, o que lhe tira importância teórica. Mas é fundamental ter mecanismos institucionais que garantam a consolidação financeira, ou seja, o direcionamento da poupança para o financiamento de longo prazo. Portanto, não é a poupança que é importante, mas a preferência dos poupadores pela liquidez que pode inibir a demanda efetiva reduzindo investimento.

Ao mesmo tempo, há um papel para o estado porque ele pode acalmar a preferência pela liquidez dos agentes econômicos ao estimular a economia e pode fazer isso tanto com política monetária quanto com política fiscal. Com política monetária pode estimular taxas de juros baixas, tornando as condições financeiras favoráveis, vis-à-vis às expectativas de rendimentos futuros para maior número de investidores, intervindo assim sobre ofinance motive. O estado pode ainda estimular o desenvolvimento dos mercados financeiros de forma que acomodem melhor - com produtos financeiros distintos em termos de liquidez e rentabilidade - tanto as preferências pela liquidez dos poupadores quanto as maturidades diferentes dos investimentos, garantindo, neste último caso, um funding mais fácil.

Em qualquer desses casos, porém, é difícil garantir sempre bons resultados, porque eles dependem da subjetividade dos bancos e dos agentes quanto à percepção da incerteza e, consequentemente, das diferentes preferências pela liquidez. Se elas forem grandes, isso impedirá os gastos de investimento e mesmo de consumo e a economia não será estimulada. Daí a preferência de Keynes pela política fiscal, dependendo apenas do governo que, sem objetivo de lucro, pode empreender gastos de investimento. Estes, aumentando a renda e o emprego, não apenas estimulam diretamente a economia, mas interferem também nas preferências pela liquidez e nas expectativas dos empresários e demais agentes econômicos, devolvendo-lhes o otimismo e garantindo o crescimento econômico.

Ao separar os gastos correntes do governo dos gastos em investimento, por outro lado, Keynes consegue mostrar a pertinência de políticas fiscais ativas que substituam e estimulem a ação da iniciativa privada, sem que isso comprometa as finanças estatais, porque a arrecadação aumentará necessariamente quando a economia investir e crescer, sem sobrecarregar o setor privado com aumento de alíquotas (Lopes; Mollo, 2011).

Ao mesmo tempo, há um papel para a política monetária tanto no processo de financiamento quanto no de consolidação do investimento, reduzindo a taxa de juros dos ativos líquidos. Ao reduzir a taxa básica de juros, a tomada de empréstimos 
de maior número de investidores é estimulada porque, para maior número deles, a eficiência marginal do capital será maior do que a taxa de juros. Satisfaz-se, assim, ao motivo financiamento de demanda de dinheiro (finance motive). Ao mesmo tempo, a taxa de juros de curto prazo não inibirá o funding do investimento, já que a taxa de longo prazo, que contém sobre a de curto prazo um prêmio de liquidez, também será baixa.

Assim, a variável-chave para os novos desenvolvimentistas pós-keynesianos não é a taxa de câmbio, como para os precursores, mas a de juros. Por um lado, ela viabiliza, conforme mencionado, tanto o finance quanto o funding do investimento. Por outro, taxas de juros baixas melhoram as contas públicas e são ainda o melhor controle contra a entrada de capitais especulativos. É certo que a taxa de câmbio também tem importância para essa vertente do pensamento. Todavia, o controle da taxa de juros é priorizado porque, tendo em vista a liberalização da economia brasileira, se ela é alta, atrai capitais especulativos que a vulnerabilizam, tiram margem de manobra da política monetária (Prates, 2005; Amado; Resende, 2007) e inibem o investimento produtivo doméstico. Nesse sentido, a taxa de juros baixa funciona como excelente controle de capitais e estimula o investimento produtivo ${ }^{5}$.

Quanto à distribuição da renda no detalhamento das políticas, embora Carneiro (2012) dê conta de pouca preocupação a esse respeito, ela é pelo menos mencionada em algumas das proposições dos novos desenvolvimentistas póskeynesianos (Sicsú et al., 2005, p. XLIII). Segundo estes, o novo desenvolvimentismo "relaciona-se à adoção de um conjunto de medidas que visam aumentar o nível de demanda agregada para criar um ambiente estável que estimule os empresários a realizar novos investimentos". A estabilidade com a qual estão preocupados é "a estabilidade macroeconômica, um conceito mais amplo do que o de mera estabilidade de preços, ou seja, deve procurar também reduzir as incertezas relativas à demanda futura que são inerentes aos negócios na economia".

Destaca-se ainda entre as preocupações, a de garantir mercado forte, mas regulálo, de forma que a concorrência não leve à concentração ou monopólio, com desemprego, falências, aumento de preços e redução da qualidade dos produtos. Preocupa-se também em contar com um Estado atuante para enfrentar a vulnerabilidade externa, para facilitar a transferência de tecnologia e sua absorção pelo aparelho produtivo, através de um sistema nacional de inovação, e para auxiliar na qualificação dos trabalhadores e nas transformações produtivas. Finalmente, buscam equidade, o que requer como condição garantir crescimento a taxas elevadas e continuadas.

(5) Observe-se que a taxa de juros alta dos títulos públicos inibe o investimento, porque atrai recursos para ativos líquidos como os títulos públicos. Esses recursos, de outra forma, seriam destinados a consolidar (funding) os investimentos produtivos, fornecendo recursos de médio e longo prazo compatíveis com os seus prazos de maturação. É assim que a taxa de juros inibe a demanda de investimento. 
Observe-se, aqui, que a ideia de crescimento para garantir equidade apoiase na concepção pós-keynesiana de estímulo ao investimento para aumento multiplicado da renda e do emprego, mas não há menção a aumento da demanda interna, como chamam atenção Morais e Saad-Filho $(2011)^{6}$. É que o foco aqui ainda é o mercado externo mas, diferentemente da proposta precursora, nesta abordagem, "o protecionismo moderno é o da conta de capitais" (Sicsú et al., 2005, p. XLVI), de forma a garantir menor vulnerabilidade externa à economia brasileira. Por isso a variável-chave é a taxa de juros, que precisa ficar baixa para ao mesmo tempo estimular o investimento e desestimular a entrada de capitais especulativos que apreciam a moeda nacional com todas as suas consequências nefastas.

Ao tratar das economias periféricas, alguns pós-keynesianos introduzem as ideias monetário-financeiras de Keynes - que fazem a grande diferença entre o seu pensamento de depois da Teoria Geral e a economia neoclássica - mas para apreender as restrições estruturais das economias periféricas, usam a perspectiva estruturalista ao analisar a economia real. Nesse sentido, trabalham com uma análise dual. Esses trabalhos deixam clara a necessidade de intervenção do Estado para romper com os círculos viciosos de natureza real e monetária que impedem o desenvolvimento de economias periféricas (Dow, 1982, 1987, 1990, Amado, 1997, Resende; Amado, 2007, Rodriguez Fuentes, 2005).

\subsection{Os social-desenvolvimentistas}

As políticas de distribuição de renda têm lugar de destaque no terceiro grupo de desenvolvimentistas atuais, que busca o desenvolvimento tendo como força motora o mercado interno (Bielschowsky $(2001,2002,2012)$. Tendo em vista o interesse no aumento dos salários e na distribuição de renda, essa corrente é denominada social desenvolvimentismo ou desenvolvimentismo distributivo orientado pelo Estado, como propõe Bastos (2012). Dadas tais preocupações, para garantir o consumo de massas, essa abordagem é próxima também da tradição marxista.

A tradição marxista, em matéria de desenvolvimento, é por vezes colocada próxima à ortodoxia, no que tange ao desenvolvimento estimulado pelo Estado por meio de estímulos salariais. A ideia é que como o desenvolvimento duradouro depende da poupança financiando o investimento, e como esta sai dos lucros, não é possível conceber como viável um crescimento estimulado por aumentos de salários, independente da produtividade do trabalho. Os marxistas são por vezes associados a

(6) Observe-se que a busca de equidade é afirmada sem detalhar como se fará e em que sentido é definida a equidade. Também a Cepal prescreve crescimento com equidade, mesmo nos anos 1990, anos em que a Cepal tem um receituário muito mais liberal do que os primeiros desenvolvimentistas (Fajnzylber, 2000). De qualquer forma, segue-se aqui a ideia já mencionada de Prebisch (1991), para quem a desconcentração de renda e o aumento das rendas mais baixas é fundamental para o desenvolvimento. 
essa visão porque percebem a importância da lógica de lucro no capitalismo e reconhecem que, no interior desta lógica, não há como esperar solução do problema da exploração, base do lucro. Lavoie e Stockhammer (2012), por exemplo, chamam atenção para o fato de que alguns marxistas acham que políticas econômicas prótrabalhadores não funcionam em um regime que busca o lucro, o que os leva a considerar que tais efeitos não tendem a durar muito. Entretanto não há, no interior da teoria marxista, consenso sobre o papel do Estado e, conforme a posição dos mesmos, há espaço para melhorias da inserção do trabalhador na relação capitaltrabalho com políticas desenvolvimentistas de aumento dos salários.

O debate marxista sobre o papel do Estado é histórico e há em particular uma grande controvérsia que se estabeleceu a partir dos trabalhos de Poulantzas (1971) e Miliband (1973) no início dos anos 1970 e que divide até hoje as concepções. Para Poulantzas (1971, p. 40), o Estado é "fator de coesão" dos níveis econômico, político e ideológico, com função de regulação de equilíbrio global de uma formação social. Nessa perspectiva, percebe-se uma autonomia relativa do Estado com relação às classes. Na segunda alternativa, baseada em Miliband (1973, p. 87), não há autonomia alguma, uma vez que o Estado é o braço da burguesia, já que a dominação política do capital é vista como ligada à monopolização do poder político e econômico.

Derivadas dessas duas posições, em termos mais modernos, temos a posição de autores como Jessop (1991), para quem "enquanto o keynesianismo era a expressão ideológica da tentativa do capital e do Estado de responder a aspirações generalizadas da classe trabalhadora no boom do pós-guerra, o neoliberalismo é a expressão ideológica da subordinação das aspirações da classe trabalhadora à valorização do capital". A outra posição é a de Holloway (1991, p. 251), que embora entenda que a esquerda deva defender ganhos de bem estar já obtidos pelos trabalhadores, pensa que "such a strategy misses an opportunity of exploiting the destabilising potencial inherent in the retraction of the state".

A visão de Estado que aqui se utiliza para entender a posição dos marxistas que defendem o desenvolvimentismo e, em particular, o desenvolvimentismo-social é a primeira, porque é justamente a ideia de autonomia relativa do Estado com relação às classes que permite, do ponto de vista teórico, esperar que se possa contar com o Estado e suas políticas para melhorar a condição dos trabalhadores ou sua posição na relação capital-trabalho, e é isso que justifica a defesa do desenvolvimentismo por alguns marxistas (Mollo, 2002/2012). A outra posição, ao contrário, critica essa defesa na base da ideia de que não é possível contar com o Estado capitalista para transformar a sociedade, mas apenas com a luta de classes ${ }^{7}$.

(7) No Brasil Fiori (2011; 2012a; 2012b) tem criticado a posição desenvolvimentista de correntes mais à esquerda como os marxistas, sob o argumento de que as propostas carecem de poder de transformação. 
A defesa marxista ao desenvolvimentismo, portanto, justifica-se para o primeiro grupo, pela apreensão de que ao garantir maior quantidade de empregos ele amplia o poder de barganha do trabalhador, ampliando seu salário e inserindo-o melhor na relação capital-trabalho.

Esse efeito mais direto e a curto prazo, porém, não é o único. Após os mencionados debates sobre o Estado entre os marxistas, nos anos 1970, em Postcript publicado em segunda edição em 1980, quando os efeitos das políticas monetaristas neoliberais de Tachter já se faziam sentir, o London-Edinburgh Weekend Return Group (Lewrg, 1980, p. 123) observa que a intervenção estatal fornecia “[...] ao menos uma base a partir da qual organizar a ação coletiva".

Finalmente, no que se refere ao argumento de neutralidade da moeda, a negativa marxista é terminante, uma vez que o crédito pode potencializar a produção e ampliar a capacidade produtiva da economia ampliando-lhe a escala e o ritmo, sincronizando melhor as várias fases da reprodução do capital, evitando, desta forma, o crescimento proporcional dos preços como reza a Teoria Quantitativa da Moeda (Mollo, 2004). Nesse sentido, o papel monetário do Estado pode ser e é estimulante do crescimento da produção, da renda e do emprego. Por outro lado, o crédito pode agravar as crises, o que é uma outra forma, embora negativa, de mostrar a não neutralidade da moeda.

A variável-chave para o desenvolvimentismo social é o consumo de massas, que deve ser estimulado. A dimensão potencial do mercado interno de consumo de massa representa, para Bielschowsky (2012), 'extraordinária oportunidade'. A produção e o consumo de massa no país permitem aumentar os rendimentos de escala, o progresso técnico e ainda a elevação dos salários. Permite ainda aproveitar os encadeamentos produtivos da produção de bens finais de consumo popular, inclusive os de maior intensidade tecnológica, integrando, de forma virtuosa, o crescimento e a distribuição de renda. Por isso, o consumo de massa é considerado um dos três motores do desenvolvimento econômico, juntamente com os recursos naturais e a infraestrutura, com tais motores podendo ser 'turbinados' pela formação de encadeamentos produtivos tanto nos setores tecnologicamente nobres quanto em setores produtivos tradicionais.

Nessa proposta, observa-se cautela na prescrição de taxas de câmbio competitivas, porque a desvalorização da moeda doméstica tem efeitos inflacionários que reduzem os salários. Além disso, a política industrial, apenas com câmbio, mantém a matriz tecnológica e os problemas dela decorrentes, o que é outro argumento para focar no mercado interno (Mollo; Fonseca, 2013). Finalmente, contar com o mercado interno como motor ou como estratégia leva a maior garantia de distribuição de renda e de aumento das rendas mais baixas do que quando isso é apenas resultado esperado do crescimento movido pelo mercado externo. Conta-se, nesse caso, com o apoio amplo 
do empresariado a uma situação que, ampliando o poder de barganha dos assalariados, insere melhor o trabalhador na relação capital-trabalho.

\section{Regimes de crescimento e estratégias de desenvolvimento: tomando partido}

De forma a tomar partido de um dos tipos de desenvolvimentismo apresentados, este item resume inicialmente alguns aspectos do debate sobre regimes de crescimento, levantando argumentos para justificar a posição assumida.

Chama-se regime de crescimento à forma tomada pelo crescimento econômico conforme o tipo de estímulo que produz efeitos dominantes sobre as taxas de crescimento da economia. Interessa-nos aqui tratar dos efeitos da demanda, uma vez que nos atemos à perspectiva heterodoxa. As demandas podem ser derivadas do exterior ou do próprio país internamente, pode ser demanda privada ou do governo e, seguindo essa lógica, a sugestão de Hein e Mundt (2012), é de que os países podem ser classificados em quatro grupos quanto às demandas estimuladas: a) por dívidas que sustentam o consumo; b) fortemente por exportações; c) por demanda interna; ou d) moderadamente por exportações. Segundo os autores, essa divisão é útil para entender a evolução recente dos vários países e a influência da financeirização e da queda das rendas do trabalho para a crise que se inicia em 2008, assim como ajuda a discutir a melhor forma de se desvencilhar dos seus efeitos.

Nas economias movidas pelo consumo financiado por dívidas, segundo os autores, observam-se grandes déficits do Balanço de Pagamentos e dívidas privadas e públicas que permitem a compensação das quedas de consumo corrente ocorridas em virtude da redução das rendas do trabalho no período neoliberal. As economias em que a demanda é fortemente constituída por exportações compensam a nível macroeconômico internacional as primeiras, fornecendo a produção demandada por elas. Essas são economias ditas mercantilistas, uma vez que possuem elevados superávits no Balanço de Pagamentos, que compensam a fraca demanda interna. As economias dirigidas pela demanda interna apresentam também déficits no Balanço de Pagamentos, mas não mostram um setor público ou privado particularmente endividado. Finalmente, as economias consideradas moderadamente dirigidas por exportações, onde o Brasil é situado pelos autores, são aquelas que apresentam algum superávit que compensa uma demanda interna fraca. Os autores analisam os diversos países entre 1980 e o início dos anos 2000, ficando fora da análise ou sendo compensados pelos anos anteriores, aqueles anos em que no Brasil se observa maior redução da desigualdade.

É no interior de cada um desses regimes de demanda que podemos introduzir outra característica referente à distribuição de renda dos países, qual seja, a divisão entre economias wage-led e profit-led, conforme os efeitos de mudanças na 
distribuição funcional da renda sobre o processo de acumulação da economia. Ou seja,

a wage-led demand regime means that an increase in the wage share leads to an increase in aggregate demand. The wage-led scenario may arise when higher wages led to higher consumption expenditures (higher consumption sales may then also induce higher investment expenditures). Conversely, a profit-led demand regime means that an increase in the wage share leads to a decline in aggregate demand (Stockhammer, 2011, p. 5).

Quando os salários aumentam o consumo aumenta e, com ele, o produto e o emprego. Mas trabalhos como os de Rowthorn (1981) e Dutt (1987) mostram que quando a parcela dos salários aumenta, isso aumenta também o investimento (efeito aceleracionista), estimulado por aumentos de venda e capacidade utilizada. Mas a elevação dos salários, pelo lado dos custos, afeta negativamente as margens de lucro e a lucratividade das empresas (efeito lucratividade), impactando neste sentido negativamente o investimento e o crescimento. Trabalhos como os de Marglin (1990) e de Kurz (1990) tratam disso.Como destacam Lavoie e Stocknammer (2012, p. 11),

If the profitability effect is weak (relative to the consumption effect and the accelerator effect), with the investment function not dropping below ..., then both GDP and investment are higher following the increase in real wages. In this case, both the short-runand the long-run effects are favourable to the economy. We will then say that the economy is experiencing a wage-led demand regime as well as a wage-led investment regime, since GDP is rising in the short-run but is also likely to grow faster in the long-run, thanks to the higher rate of investment. In the intermediate case, the profitability effect will lead to a shift of the investment curve somewhere between .... In this case, higher real GDP generates a higher output level but investment will be lower. We will then say that the economy is still in a wage-led demand regime, while belonging to a profit-led investment regime. This is because GDP is rising in the short-run, but likely to grow more slowly in the long-run, due to the lower investment level. Finally, we have the third case, which occurs when the profitability effect shifts the investment function below the I2 curve, meaning that the increase in real wages provokes a reduction in real output and a reduction in investment expenditures. This case corresponds to both a profitled demand regime and a profit-led investment regime.

Esse debate é criticado do ponto de vista marxista (Dos Santos, 2013a; 2013b), a partir do circuito de reprodução do capital. A crítica é sobre a ideia de que é a prescrição de estratégias de crescimento baseadas no aumento de salários que eleva o consumo de massa, mostrando que, dentro desta abordagem, não há espaço para a associação entre produto e salário real requerida pelo crescimento liderado pelos salários. Apoiando-se em modelos de Foley (1982 e 1986), que concebem os 
fluxos de salários e lucros surgindo em momentos diferentes do tempo no ciclo completo de reprodução do capital, estes trabalhos mostram relações entre a produção e a distribuição diferentes das propostas nos modelos de crescimento wageled.

Como se sabe, do ponto de vista marxista, o ciclo completo de reprodução do capital, representado por D-M (FT e MP) - ....P....M'-D', é pensado de forma dinâmica, envolvendo, em um primeiro momento, gastos monetários ou adiantamentos feitos pelos capitalistas com salários e compras de meios de produção (D-M (FT e MP) que, em um segundo momento, no processo produtivo (P), dão origem às mercadorias cujo valor é maior do que o valor adiantado (M'). Só em um terceiro momento surgem os lucros, a partir das vendas das mercadorias produzidas (D'). Nesse processo, a distribuição não é mera repartição da produção, mas ocorre em momento distinto, com os salários dependendo dos adiantamentos de capital feitos no início do ciclo, enquanto os lucros se realizam a partir das vendas realizadas no final. Nesse sentido, diferentemente dos modelos de crescimento wage-led, os salários e os lucros são determinados como consequência do processo de reprodução do capital, e não como consequência de distribuição prévia ou em razão de determinação simultânea com o produto dividido entre salários e lucros.

Utilizando o ciclo completo de reprodução do capital, ao contrário do que pensam os defensores do crescimento liderado pelos salários, o que aumenta a participação dos salários no conjunto da distribuição não é o consumo de massa, mas os investimentos, porque significam emprego e pagamento de salários, enquanto o consumo de massa afeta os lucros dos capitalistas no momento das vendas. Nesse sentido, o argumento conclusivo de tais modelos é de que ao invés da discussão sobre a opção de crescimento ser wage-led ou profit-led, a discussão correta deveria ser a da escolha entre crescimento liderado por investimento ou consumo de massa, no primeiro caso para aumentar salários.

Examinando a literatura recente sobre o assunto, observa-se que várias são as razões que nos levam a concluir pela maior adequação da proposta socialdesenvolvimentista, razões que sumariaremos aqui de forma conclusiva:

1. Não existem para o Brasil muitos estudos que definam se o modelo de crescimento é wage-led ou profit-led. Estudo recente, de Miguel Bruno (2012), encomendado pelo IPEA, chega à conclusão de que o Brasil é wage-led. Apesar disso, os novos desenvolvimentistas precursores estão propondo queda dos salários sob a alegação de que o regime brasileiro é profit-led e requer isso para tornar as exportações competitivas, afirmando ainda que o sistema de crescimento wage-led não é sustentável a longo prazo (Oreiro, 2012). A descrição que Onaran e Stockhammer (2002) fazem acima da estratégia turca até meados 
dos 1990 mostra enorme insucesso da estratégia, com a retração dos salários sendo incapaz de estimular novos investimentos produtivos na indústria.

2. A proposta de crescimento export-led, como discute Palley (2012), é parte das prescrições baseadas no consenso dominante na ortodoxia liberal, juntamente com: a) o teorema Hecksher-Ohlin-Samuelson, que enaltece os benefícios do comércio quando as relações capital-produto são diferentes; b) a ideia de que a abertura disciplina os governos e evita o problema de rent-seeking; c) assim como a ideia de spillovers de conhecimento contribuindo para o crescimento com a abertura para o exterior. Nenhuma das conclusões esperadas pelas teorias acima resiste aos resultados que hoje temos no mundo sobre aumento de desigualdade, crises e dificuldades generalizadas de retomada do crescimento após o neoliberalismo.

3. Vários são os estudos, além disso, que mostram a predominância de economias wage-led no mundo. Consolidando os resultados de vários estudos sobre o assunto, Onaran e Galanis (2012) encontram a predominância de resultados em que os países do ponto de vista da demanda doméstica são wageled, embora em alguns casos tornem-se profit-led quando introduzido o comércio externo. Eles próprios, analisando 16 dos países do G20 para os quais estavam disponíveis dados, chegam a essa conclusão. O Brasil é um dos quatro países não analisados, segundo os autores, por inexistência de dados. Para os 16 países apresentados, os autores concluem que, em virtude do consumo ser mais sensível a um aumento do lucro do que o investimento, todos os países contam com uma demanda doméstica que é wage-led. Assim, uma economia é profit-led apenas quando o efeito de distribuição nas exportações líquidas é grande o bastante para compensar os efeitos na demanda doméstica. Os autores concluem ainda que, mesmo que algumas economias sejam profit-led, a economia mundial como um todo é wage-led. Assim, por um lado se, em vista da integração das economias, há uma baixa dos salários, a economia global se contrai, e isso cria problemas até para os poucos países que são profit-led. Por isso, os autores concluem que políticas "beggar thy neighbour" são contraproducentes. Essas análises mostram como é discutível o uso de exportações para dirigir o crescimento. Além do país ficar sempre vulnerável ao que ocorre no exterior, fora do seu controle, as perspectivas apresentadas nesses estudos já dão conta de uma situação pouco favorável no resto do mundo no que se refere a essa estratégia.

4. Autores como Palley (2011) chamam ainda a atenção para alguns outros problemas relativos à estratégia de crescimento export-led: a queda global de demanda com a crise e a saturação da demanda financiada por crédito nos Estados Unidos reduzem a demanda global; o tamanho das economias emergentes faz com que suas exportações estejam sabotando a reconstrução das economias industrializadas, o que coloca de novo problemas para o crescimento 
da demanda global; a tentativa de ganhar fatias desta demanda reduzida tende a levar os países emergentes à concorrência acirrada, baixando salários e regulamentações e minimizando preocupações com problemas ambientais. Segundo Palley, isso só beneficiará as corporações multinacionais que contam com elevadas margens de lucro, o que, de novo, mostra o caráter regressivo do ponto de vista da distribuição da renda da estratégia export-led; uma vez que a China adote uma estratégia do tipo export-led, para aproveitar seu excesso de mão de obra e seus baixos salários, a competição sul-sul ficará ainda mais difícil.

Se as observações feitas até aqui referem-se a problemas da estratégia export-led, opondo-se por aí ao novo desenvolvimentismo precursor, as próximas observações apontam para as vantagens que tornam o social desenvolvimentismo superior às demais perspectivas desenvolvimentistas.

1. Em primeiro lugar, e mais importante, a estratégia é substancialmente melhor do ponto de vista de justiça social.

2. Em segundo lugar, usa como motor do desenvolvimento a demanda interna que, não apenas tem se mostrado importante ao longo da história, mas que, recentemente, mostrou de fato seu elevado potencial, garantindo taxas de crescimento expressivas pela primeira vez em várias décadas.

3. Em terceiro lugar, reconhece-se amplamente, tanto nas posições mais à esquerda quanto nas mais à direita, que o grande problema econômico da economia brasileira no momento está na indústria, mais particularmente na sua incapacidade de crescer nos últimos anos, o que tem travado o crescimento da economia como um todo. Ora, a estratégia social-desenvolvimentista propõe turbinar o crescimento com a formação de encadeamentos produtivos tanto nos setores tecnologicamente nobres quanto em setores produtivos tradicionais. Sabemos que os efeitos de encadeamento são particularmente importantes (principalmente os para trás, que contemplam o lado da demanda) no setor industrial. Assim, estaríamos não apenas resolvendo o grande problema de desindustrialização vivido pelo Brasil, mas estaríamos fazendo isso com políticas industriais deliberadas, que potencializassem os ganhos não apenas em termos de demanda interna, mas ainda de escala, e de ganhos tecnológicos associados a esse desenvolvimento. Tudo isso garantindo aumentos de emprego e salários, e, assim, inserindo melhor os trabalhadores na relação capital-trabalho.

4. Quanto à proposta de modificar a discussão para focar a escolha entre o crescimento liderado por investimento ou por consumo de massa, nossa opinião é que, em primeiro lugar, o aumento do investimento precisa ser priorizado entre as medidas de política econômica para garantir o crescimento da massa de salários no conjunto da distribuição, proporcionado pelo próprio andamento do ciclo completo de reprodução do capital, como no modelo 
marxista, garantindo assim melhor inserção do trabalhador na relação capitaltrabalho. Em segundo lugar, os modelos que discutem a opção entre crescimento via investimento ou estimulado pelo consumo mostram que, se o estímulo é ao mercado interno, mesmo que encabeçado pelo consumo, ele não inibe o investimento por aumento de salários, como pensam os desenvolvimentistas precursores, porque o que aumenta com o consumo é a fatia de lucros, influindo positivamente na decisão de investir.

5. Mas uma vez garantido o aumento de salários endógeno, a partir do investimento, nada impede que transferências governamentais ou determinações legais de aumentos de salário mínimo, por exemplo, possam diretamente e exogenamente aumentar ainda mais a fatia de salários, para melhorar de novo a inserção do trabalhador na relação capital-trabalho. Assim, teríamos dois aumentos de salários, um endógeno e o outro exógeno, sendo que esse último contaria com o apoio dos capitalistas beneficiados com o consumo de massa dele proveniente, se o mesmo, como teoricamente apontado, levar a aumentos dos lucros, objetivo dos capitalistas.

6. Os mesmos modelos que se baseiam no ciclo completo de reprodução do capital (Dos Santos, 2013b) mostram bem que o estímulo ao crescimento via crédito, para ser mais inclusivo ou mais favorável aos trabalhadores, deve ser dado ao investimento e não ao consumo, o que também é defendido pelos pós-keynesianos na base do efeito multiplicador de renda e emprego que o investimento provoca.

7. Por último, mas muito importante, a retomada dos investimentos deveria priorizar o setor industrial, como já afirmava Bielschowsky (2012), e como mencionado anteriormente, e é mais provável que isso seja facilitado se a estratégia é a da demanda interna, uma vez que pesquisas vêm mostrando que os empresários respondem melhor a esse tipo de demanda do que à externa (Bielschowsky, 2002).

\section{Considerações finais}

Descrevemos até aqui os vários tipos de desenvolvimentismo brasileiros na atualidade, destacando suas raízes teóricas e as prescrições de política consequentes. Em particular, destacamos as variáveis-chave nessas prescrições, quais sejam a taxa de câmbio competitiva dos novos desenvolvimentistas precursores, a taxa de juros baixa dos novos desenvolvimentistas pós-keynesianos e o consumo de massa dos social-desenvolvimentistas. Em todos os casos, tais prescrições buscam um aumento de demanda que garanta impulso ao crescimento da economia, daí seu caráter heterodoxo. 
Colocamo-nos do lado dos social-desenvolvimentistas, em particular pela melhor inserção dos trabalhadores na relação capital-trabalho que propicia, ampliando seu poder de barganha nas negociações salariais e viabilizando maior poder de organização para ganhos maiores. Tal estratégia, todavia, embora apoiada no aumento do consumo que, por si só, tende a estimular o investimento, ganha também com as taxas baixas de juros prescritas pelos novos desenvolvimentistas pós-keynesianos. Também os novos desenvolvimentistas precursores, como vimos, as defendem, o que torna as taxas de juros baixas uma unanimidade heterodoxa.

As desvalorizações competitivas da moeda nacional, porém, precisam ser vistas com cautela. Por um lado, podem e devem evitar a exportação de empregos que vem ocorrendo com a desindustrialização brasileira, mas é preciso evitar que o impacto dela sobre a inflação reduza os salários reais. Em qualquer caso, diferentemente do que pensa a ortodoxia liberal, a taxa de câmbio é importante demais para ficar ao sabor do mercado, precisando ser administrada.

Finalmente, é principalmente o lado da demanda de investimentos que precisa ser priorizado, seja para aumentar a capacidade produtiva, emprego e os salários sem pressões inflacionárias, ou para adaptar as estruturas produtivas às nossas especificidades e desenvolver padrões tecnológicos próprios.

\section{Referências bibliográficas}

AMADO, A. M. Disparate regional development in Brazil: a monetary production approach. Aldershot: Ashgate, 1997.

; Resende, M. F. C. Liquidez internacional e ciclo reflexo: algumas observações para a América Latina. Revista de Economia Política, v. 27 n. 1 (105), p. 41-59, jan./mar. 2007.

BASTOS, P. P. Z. A economia política do novo-desenvolvimentismo e do social desenvolvimentismo. Economia e Sociedade, Campinas, v. 21, Número Especial, p. 779-810, dez. 2012.

BIELSCHOWSKY, R. Pensamento econômico Brasileiro: o ciclo ideológico do desenvolvimentismo. Rio de Janeiro: IPA/Inpes, 1988.

Anotações sobre a estratégia de crescimento elo mercado interno de consumo popular e o programa do PT para 2003-2006. São Paulo: Instituto da Cidadania, 2001. Mimeografado.

. (Coord.). Investimento e reforma no Brasil nos anos 1990. Brasília: Cepal-Ipea, 2002, cap. 2.

Vigência das contribuições de Celso Furtado ao estruturalismo. Revista de la Cepal, n. 109, 2010. 
BIELSCHOWSKY, R. Estratégia de desenvolvimento e as três frentes de expansão no Brasil: um desenho conceitual, Economia e Sociedade, Campinas, v. 21, Número Especial, p. 729-747, dez. 2012.

BRESSER-PEREIRA, L. C. (Org.) Populismo econômico: ortodoxia, desenvolvimentismo e populismo na América Latina. São Paulo: Nobel, 1991.

. Novo-desenvolvimentismo. Folha de S. Paulo, 19 set. 2004.

. O novo desenvolvimentismo e a ortodoxia convencional. São Paulo em Perspectiva, v. 20, n. 3, p. 5-24, 2006.

. Estado y mercado en el nuevo desarrollismo. Nueva Sociedad, n. 210, p. 110-125, Jul./Ago. 2007.

An account of new developmentalism and the structuralist macroeconomics. Revista de Economia Política, v. 31, n. 3, p. 493-502, 2011.

; GALA, P. Por que a poupança externa não promove crescimento. Revista de Economia Política, v. 27, n. 1, p. 3-19, 2007.

- Macroeconomia estruturalista do desenvolvimento. Revista de Economia Política, v. 30, n. 4: 663-686. 2010

; NAKANO, Y. Uma estratégia de desenvolvimento com estabilidade. Revista de Economia Política, v. 21, n. 3, p. 3-27, 2002.

- Crescimento econômico com poupança externa? Revista de Economia Política, v. 22, n. 2, p. 3-27, 2003.

BRUNO, M. Growth regime and capital accumulation in Brazil: a preliminary analysis of the liberalization period. 2012. Mimeografado.

CARNEIRO, R. Velhos e novos desenvolvimentismos. Economia e Sociedade, Campinas, v. 21, Número Especial, p. 749-778, dez. 2012.

CARVALHO, F. C. Moeda, produção e acumulação: uma perspectiva póskeynesiana. In: SILVA, M. L. F. (Org). Moeda e produção: teorias comparadas. Brasília: Ed. UnB, 1982.

DOW. S.C. The regional composition of the money multiplier process, Scottish Journal of Political Economy, v. 29, n. 1, 1982.

. The treatment of money in regional economics. Journal of Regional Science, v. 27, n. 1, 1987.

. Financial markets and regional economic development: the Canadian experience. Ashgate, 1990. 
DUTT, A. K. Alternative closures again: a comment on 'Growth, distribution and inflation'. Cambridge Journal of Economics, v. 11, n. 1, p. 75-82, 1987.

FIORI, J. L. A miséria do ‘novo desenvolvimentismo’. Carta Maior, 30 nov. 2011. . O ‘desenvolvimentismo de esquerda’. Carta Maior, 13 nov. 2012a. . Desenvolvimentismo e 'dependência'. Carta Maior, 13 nov. 2012 b.

FERRARI FILHO, F.; FONSECA, P. D. Qual desenvolvimentismo? Uma proposição à lawage-ledkeynesiano-institucionalista. In: ENCONTRO NACIONAL DE ECONOMIA, 41. Anais... Foz do Iguaçu: Anpec, dez. 2013.

FOLEY, D. Realization and accumulation in a Marxian model of the circuit of capital. Journal of Economic Theory, v. 28, n. 2, p. 300-319, 1982.

Money, accumulation and crisis. London: Harwood Academic Publishers, 1986. (Fundamentals of Pure and Applied Economics, n. 2).

FAJNZYLBER, F. Industrialização na América Latina: da "caixa-preta" ao “conjunto vazio". Cuadernos da CEPAL, Santiago do Chile, n. 60, 2000. (LC/G 1534 Ver 1-P).

HEIN, E.; MUNDT, M. Financialisation and the requirements and potential for wage-led recovery - a review focusing on the G20. Geneva: International Labour Office, 2012, (Conditions of Work and Employment Series, n. 37).

JESSOP, B. Regulation theory, post fordism and the State: more than a reply to Werner Bonefeld. In: BONEFELD, W.; HOLLOWAY, J. Post-fordism and social form: a Marxist debate on the post-fordist state. London: Macmillan, 1991.

KEYNES, J. M. Activities 1940-1946 shaping the post-war world: employment and commodities. London: MacMillan, 1980.

Alternative theories of the rate of interest. In: . The Collected Writings of John Maynard Keynes, v. 14. London: MacMillan and Cambridge University Press, 1983a.

Mr. Keynes' finance. In: The Collected Writings of John Maynard Keynes, v. 14. London: MacMillan and Cambridge University Press, 1983b.

KURZ, H. Technical change, growth and distribution: a steady-state approach to unsteady growth. In KURZ, H. (Ed.). Capital, distribution and effective demand: studies in the classical approach to economic theory. Cambridge: Polity Press, 1990, p. 210-239. 
LAVOIE, M.; STOCKHAMMER, E. Wage-led growth: concept, theories and policies. Geneva: International Labour Office, 2012. (Conditions of Work and Employment Series, n. 41).

LEWRG. The London - Edinburgh Weekend Return Group. In and against the State. London: Pluto Press, 1980.

LOPES, M. L.; MOLLO, M. L. R. O debate sobre a redução do déficit fiscal no Brasil: uma crítica pós-keynesiana. Nova Economia, v. 21, n. 1, 2011.

HOLLOWAY, J. The state and every day struggle. In: CLARKE, S. (Ed.). The state debate. London: Macmillan, 1991a.

MARGLIN, S.; BHADURI, A. Profit squeeze and Keynesian theory. In: MARGLIN; SCHOR, p.153-186, 1990.

MILIBAND, R. Poulantzas and the capitalist state. New Left Review, v. 82, Nov./Dec. 1973.

MOLLO, M. L. R. A concepção marxista de Estado: considerações sobre antigos debates com novas perspectivas. Economia, Anpec, v. 2, n. 1, jan./jun. 2001.

. Ortodoxia e heterodoxia monetárias: a questão da neutralidade da moeda. Revista de Economia Política, v. 24, n. 3, p. 323-343, 2004.

A concepção marxista de Estado: considerações sobre antigos debates com novas perspectivas. In: CHITOLINA, C. L.; PEREIRA, J. A.; OLIVEIRA, L. B.; BORDIN, R. A. (Org.). Estado, indivíduo e sociedade: problemas contemporâneos. Jundiaí: Paco Editorial, 2012.

; FONSECA, P. D. Desenvolvimentismo e novo-desenvolvimentismo: raízes teóricas e precisões conceituais. Revista de Economia Política, v. 33 n. 2 (121), 2013.

MORAIS, L.; SAAD-FILHO, A. Da economia política à política econômica: o novo-desenvolvimentismo e o Governo Lula. Revista de Economia Política, v. 31, n. 4, out./dez. 2011.

KEYNES, J. M. The Collected Writings of John Maynard Keynes, v. XIII. London: MacMillan, 1971-1983

Activities 1940-1946 shaping the post-war world: employment and commodities. In: . The Collected Writings of John Maynard Keynes, v. XXVII. London: MacMillan. 1980

Alternative theories of the rate of interest. In: . The Collected

Writings of John Maynard Keynes, v. XIV. London: MacMillan and Cambridge University Press, 1983a. 
KEYNES, J. M. Mr. Keynes' finance. In: . The Collected Writings of John Maynard Keynes, vol. XIV. London: MacMillan and Cambridge University Press, 1983b.

A teoria geral do emprego. In: LUCAS, Fábio (Org.). Economia $e$ ciências sociais. Rio de Janeiro: Zahar.

MILIBAND, R. Poulantzas and the capitalist state. New Left Review, v. 82, Nov./Dec. 1973.

ONARAN, O.; GALANIS, G. Is aggregate demand wage-led or profit-led? National and global effects. Geneva: International Labour Office, 2012. (Conditions of Work and Employment Series, n. 31).

; STOCKHAMMER, E. Two different export-oriented growth strategies under a wage-led accumulation regime: à la Turca and à la South Korea. Amherst: Political Economy Research Institute, University of Massachusetts, 2002. (Working Paper Series n. 38).

OREIRO, J. L. C. Novo-desenvolvimentismo, crescimento econômico e regimes de política monetária. Estudos Avançados, São Paulo, v. 26, n. 75, 2012a.

Wage-led versus export-led: desfazendo confusões conceituais. Macroeconomia Estruturalista do Desenvolvimento, Opinião, 24 set 2012b.

PALLEY, T. The contradictions of export-led growth. Public Policy Brief, Levy Institute of Bard College, n. 119, 2011.

POULANTZAS, N. Pouvoir politique et classes sociales. Paris: Maspero, 1971.

PRATES, D. As assimetrias do sistema monetário e financeiro internacional. Revista de Economia Contemporânea, v. 9, n. 2, Maio/Ago. 2005.

PREBISCH, R. O falso dilema entre desenvolvimento econômico e estabilidade monetária. Revista de Ciências Econômicas, 1961.

RESENDE, M. F. C.; AMADO, A. M. Liquidez internacional e ciclo reflexo: algumas observações para a América Latina. Revista de Economia Política, v. 27, n. 1, 2007.

RODRIGUEZ, O. Teoria do subdesenvolvimento da Cepal. Rio de Janeiro: Forense Universitária, 1981.

RODRIGUEZ-FUENTES, C. Regional monetary policy. New York: Routledge, 2005.

ROWTHORN, R. Demand, real wages and economic growth. Thames Papers in Political Economy, Autumn, p. 1-39, 1981. 
SANTOS. Production and consumption credit in a continuous-time model of the circuit of capital. Historical Materialism, v. 17, n. 2, p. 180-2013, 2013 a.

. Demand, production and the determinants of distribution: a caveat on

"wage-led growth". PERI - Political Economy Research Institute, May 2013b. (Working Paper Series, n. 323).

SICSÚ, J.; PAULA, L. F.; MICHEL, R. Introdução. In: NOVOdesenvolvimentismo: um projeto nacional de crescimento com equidade social. Barueri-SP: Manole; Rio de Janeiro: Fundação Konrad Adenauer, 2005.

. Por que novo-desenvolvimentismo? Revista de Economia Política, v. 27 , n. 4 (108), out./dez. 2007.

STOCKHAMMER, E. Wage-led growth: an introduction. London: Kingston University, 2011. (Economics Discussion Papers, 2011-1).

THIRWALL, A. P. Regional problems are balance of payments problems. Regional Studies, v. 14, 1980.

; THIRWALL, A. P.; HUSSAIN, M. N. The balance of payments constraint, capital Flows and growth rate differences between developing countries. Oxford Economic Papers, v. 34, n. 3, 1982. 